\title{
COMMENTARY
}

\section{Considerations for cancer immunotherapy biomarker research during COVID-19}

\author{
Jennifer W Carlisle ${ }^{1,2, *}$, Caroline S Jansen ${ }^{1,3,5, *}$, Mehmet Asim Bilen1,2 and Haydn Kissick ${ }^{1,3,4,5}$ \\ ${ }^{1}$ Winship Cancer Institute of Emory University, Atlanta, Georgia, USA \\ 2Department of Hematology and Oncology, Emory University School of Medicine, Atlanta, Georgia, USA \\ ${ }^{3}$ Department of Urology, Emory University School of Medicine, Atlanta, Georgia, USA \\ 4Department of Microbiology and Immunology, Emory University School of Medicine, Atlanta, Georgia, USA \\ ${ }^{5}$ Emory Vaccine Center, Emory University School of Medicine, Atlanta, Georgia, USA
}

Correspondence should be addressed to M A Bilen or H Kissick: mehmet.a.bilen@emory.edu or haydn.kissick@emory.edu

*(J W Carlisle and C S Jansen contributed equally to this work)

The COVID-19 pandemic continues to profoundly impact the function of medical oncology practices across the globe. With constantly evolving recommendations, clinicians are pushed to extrapolate data and apply foundational principles of oncology to balance risks and benefits for each individual and their treatment options (Lewis 2020). Large registries have been established to collect clinical and outcome data on patients with cancer who become infected with the novel SARS-CoV-2 including the American Society of Clinical Oncology Survey on COVID-19 in Oncology Registry, the American Society of Hematology Research Collaborative COVID-19 Registry, and the COVID-19 and Cancer Consortium (https://www.asco.org/ascocoronavirus-information/coronavirus-registry; https:// www.ashresearchcollaborative.org/covid-19-registry; https://ccc19.org). While patient safety and clinical care remain paramount, the immune repercussions of SARSCoV-2 viral infection on cancer immunology research efforts need to be carefully considered. Herein, we review the T-cell response to acute viral infection, explore the overlap among markers of T-cell activation in response to immunotherapy and in viral infections, highlight similarities in systemic inflammatory profiles in these two settings, and discuss practical considerations for clinical and research programs.

\section{Strategies for and considerations in monitoring the in vivo T-cell response during COVID-19}

A significant limitation in studying the T-cell response in cancer patients is not knowing the antigen specificity of the cells being monitored. To overcome this challenge, we use markers that have previously been defined to mark T-cell activation in diseases, such as viral infections, where we are much more certain of the timing and kinetics of the response. Details of what these markers mean in viral infections, how they have been used for to monitor the immune response to cancer, and how SARS CoV-2 might disrupt our use of these markers are discussed subsequently.

During viral infections, naive CD8 $\mathrm{T}$ cells that are specific to the invading pathogen are activated and undergo 15-20 rounds of cell division, resulting in a rapid, large expansion in the number of virus-specific CD8 T cells (Doherty 1998, Murali-Krishna et al. 1998, Butz \& Bevan 1998, Kalia et al. 2006). These newly expanded virusspecific CD8 T cells express effector molecules such as granzymes and perforin, which contribute to the targeted killing of infected cells. This period of proliferation and infected cell killing is often referred to as the expansion phase of the T-cell response (Fig. 1). When the pathogen has been cleared, the majority of the virus-specific CD8 $\mathrm{T}$ cells die during the contraction phase of the T-cell response. A small subset of these cells is able to persist and become memory CD8 $\mathrm{T}$ cells, which are critical for providing a rapid, antigen-specific T-cell response in the event of reinfection with the same virus (Kaech et al. 2002). The maintenance of these cells is known as the memory phase of the T-cell response.

A strong body of work has confirmed and expanded upon these findings in human studies. One tool for describing the human T-cell response to acute viral 


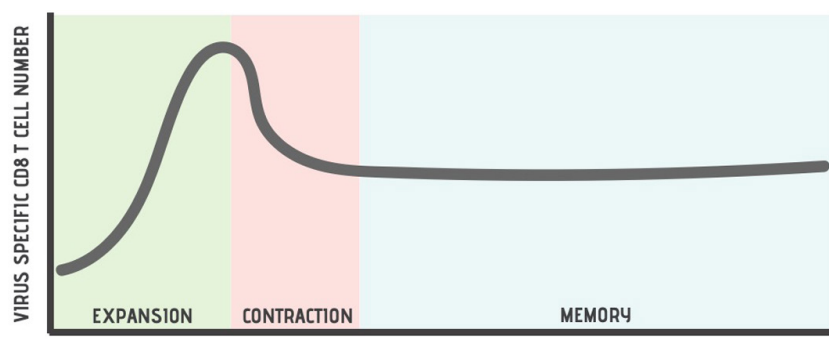

Figure 1

An illustration of the three phases of the CD8 T-cell response to acute viral infection. During the expansion phase, the number of virus-specific CD8 T cells increases. This is followed by the contraction phase, when the number of virus-specific CD8 T cells decreases. In the memory phase, this number of virus-specific CD8 T cells plateaus and remains above the baseline level.

infection is measuring T-cell responses after immunization with a live attenuated vaccine, such as the yellow fever vaccine or the Dry-Vax smallpox vaccine. In patients receiving either of these vaccines, expression of activation markers such as PD-1, HLA-DR, CD38, or Ki67 (Fig. 2) on peripheral blood mononuclear cells (PBMCs) is extremely low at baseline. Following immunization, the proportion of CD8 $\mathrm{T}$ cells expressing these markers greatly expands and their expression is largely limited to virusspecific CD8 $\mathrm{T}$ cells, indicating a rapid, large increase in newly generated, activated, virus-specific effector $\mathrm{T}$ cells. While virus-specific cells can be detected $>30$ days after immunization, they no longer express these activation markers (Miller et al. 2008, Akondy et al. 2009). Consequently, measuring the surge in T cells expressing these activation markers allows for identification of only newly generated effector CD8 T cells (Callan et al. 1998, Lechner et al. 2000, Appay et al. 2002).

Antigen-specific studies of viral infection have provided a strong foundation for establishing these measures of T-cell activation. In turn, applying this understanding more broadly allows for study of T-cell activation in settings where antigens may be unknown or too numerous, such as in cancer. Given the lack of known cancer antigens and the heterogeneous nature of human cancer, this activation marker-based approach is also commonly employed to observe the expansion phase of the tumor-related T-cell response, thereby functioning as a biomarker of response to immunotherapy. Examples of successful use of this tactic and the potential impact of COVID-19 on this approach is reviewed subsequently.

Expression of programmed cell death protein 1 (PD-1) on $T$ cells during chronic antigen exposure and subsequent 'exhaustion' is widely appreciated (Hashimoto et al. 2018), but it should be emphasized that PD-1 is expressed by recently activated cells upon exposure to their cognate antigen (Ahn et al. 2018). Accordingly, PD-1+ T cells are often evaluated in assessing the anti-tumor immune response (Jansen et al. 2019), as a readout of cells that have recently encountered their cognate antigen, in which tumor tissue is likely to enrich for tumor-specific $\mathrm{T}$ cells. Importantly, PD-1+ $\mathrm{T}$ cells in the blood are measured in response to immunotherapy. These PD-1+ cells represent a readout of $\mathrm{T}$ cells that are recently activated, and an expansion of these cells has been associated with a clinical response to immunotherapy (Kamphorst et al. 2017, Huang et al. 2017).

Much like monitoring expression of PD-1 on CD8 $\mathrm{T}$ cells, Ki67 expression is also used as a biomarker for assessing response to immunotherapy. Ki67 is a nuclear protein that is active in all phases of the cell cycle, but is absent in quiescent (G0) cells (Bruno \& Darzynkiewicz 1992), and thus, it is commonly used as a readout of cell proliferation. Newly activated $\mathrm{T}$ cells are known to undergo several rapid, obligatory rounds of proliferation following antigenic stimulus (Kaech \& Ahmed 2001). Accordingly, measurement of Ki67+ proliferating cells can be used as an indicator of recent CD8 T-cell activation and thus can approximate the anti-cancer immune response.
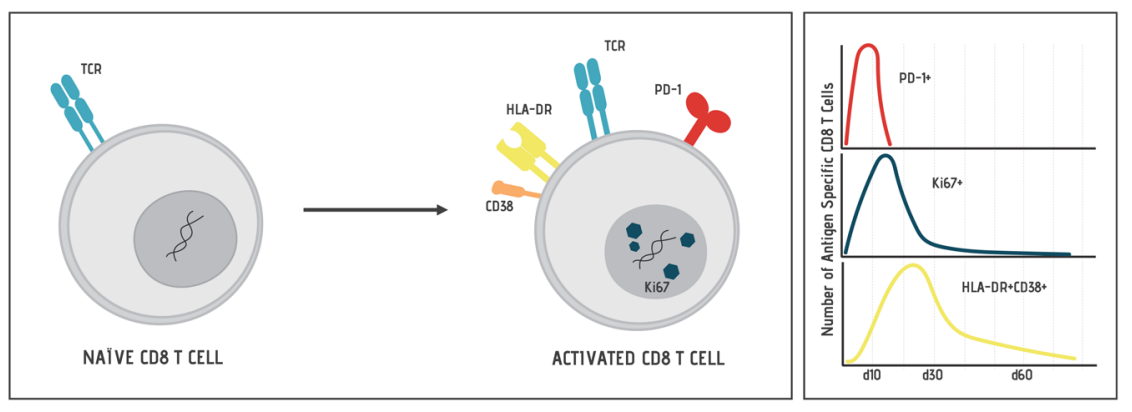

\section{Figure 2}

An illustration of the dynamic expression of proteins that indicate CD8 T-cell activation. Activation markers PD-1, Ki67, HLA-DR, and CD38 are not present on naive cells, but are upregulated upon CD8 T-cell activation. Expression of PD-1 is most acute, rising and falling rapidly. The number of Ki67 expressing cells rises and falls as the antigen-specific CD8 T-cell population grows and then shrinks during the expansion and contraction phases of the acute immune response. The number of HLA-DR+ CD38+ cells also increases following antigen exposure, gradually decreasing as the immune response resolves. 
For example, an increase in Ki67+ CD8 $\mathrm{T}$ cells in the blood following PD-1 blockade is associated with clinical response (Kamphorst et al. 2017, Huang et al. 2017). In addition to use as a readout for tumor-specific $\mathrm{T}$ cells in the blood following immunotherapy (Huang et al. 2017), measurement of Ki67+ T cells in tissue has been used to predict patient outcomes in renal cell carcinoma (Nakano et al. 2001).

Similarly, the co-expression of HLA-DR and CD38 on CD8 T cells can be used as a marker of recent activation (Appay et al. 2002, Miller et al. 2008, Akondy et al. 2009). The co-expression of these molecules closely mirrors expression of Ki67(Wieland et al. 2018), indicating that these recently activated cells are proliferating and suggesting they are likely responding to their cognate antigen. Indeed, expression of HLA-DR and CD38 has been reported on Ki67+ CD8 T cells in the blood of immunotherapy-responsive patients (Kamphorst et al. 2017, Huang et al. 2017), as well as on tumor-infiltrating lymphocytes in cancers such as glioma, ovarian cancer, melanoma, and colorectal cancer (KovacsovicsBankowski et al. 2014, Chen et al. 2019). Similarly, an increase in HLA-DR expression on tumor-infiltrating CD8 T cells has been observed following immunotherapy (Daud et al. 2016).

Understanding the role of each of these markers in the biology of the T-cell response has enabled powerful analysis of the anti-tumor immune response and the response to immunotherapy in the absence of robust and accessible techniques for assessing cancer antigen specificity. However, it is important to note that expression of these markers is not specific to activation of the cancer-related immune response. For example, the surge in activation marker expression 14 days following yellow fever vaccination can be attributed to the generation of many new effector CD8 T cells specific for the virus (Miller et al. 2008, Akondy et al. 2009). Similarly, assessment of activated CD8 T cells (HLA-DR+, CD38+) was used to describe the immune response of patients acutely infected with Ebola virus, prior to specific major histocompatibility complex tetramer development (McElroy et al. 2015). Thus, assessment of the response to viruses as they emerge, such as Ebola in 2014 and SARS-CoV-2 presently, often relies on these more general readouts of immune activation. This lack of inherent specificity is an increasingly important consideration amidst the SARS-CoV-2 pandemic, particularly in the context of currently utilized biomarkers of the response to immunotherapy.
While much remains unknown about the specific kinetics of the T-cell response to SARS-CoV-2, we can reasonably infer from previous studies of acute viral infections that the immune response to this virus will be associated with an acute T-cell response (Fig. 1). As has been reviewed previously, this acute response will include an expansion in activated T cells, which, without tools for evaluating the antigen-specific immune response, would be indistinguishable from activated $\mathrm{T}$ cells responding to a patient's tumor. For example, if a patient receiving immunotherapy became infected with SARS-CoV-2, the viral immune response would obscure accurate measurement of the response to immunotherapy, as an increase in circulating PD-1+, or Ki67+, or HLA-DR+CD38+ T cells could be attributable to either the received immunotherapy, the ongoing viral infection, or both. Accordingly, it will be imperative to know patients' SARS-CoV-2 infection status in order to accurately interpret results from studies that monitor responses to immunotherapy or that include measures of the immune system as biological correlates.

\section{Concurrent use of inflammatory markers in oncology and COVID-19}

Long-standing chronic inflammation is known to be a risk factor for the development of cancer, and measurement of inflammatory markers - such as IL-6, neutrophil to lymphocyte ratio (NLR), and C-reactive protein (CRP) - is increasingly appreciated as predictors of prognosis and/or the response to therapy in a variety of tumor types (Table 1). As sustained inflammation is suggested to mediate some severe complications of COVID-19, many of these markers are also being investigated in the setting of SARS-CoV-2 infection. The overlap between these two applications of blood inflammatory markers offers both reason for special consideration of cancer patients as 'high risk' amidst the COVID-19 pandemic and potential insight into understanding the pathogenesis of these inflammatory states.

Neutrophil to lymphocyte ratio (NLR) has been used as an inflammatory marker for a variety of conditions, including cardiovascular disease, stroke, metabolic syndrome, rheumatoid arthritis, and chronic obstructive pulmonary disease (Gibson et al. 2007, Chandrashekara et al., 2017, Goyal et al. 2018, Ye et al. 2019). NLR has also been investigated as a biomarker for cancer-related prognosis, disease recurrence, and therapeutic response. 
Table 1 Blood inflammatory markers.

\begin{tabular}{ll}
\hline $\begin{array}{l}\text { Neutrophil to } \\
\text { lymphocyte ratio (NLR) }\end{array}$ & $\begin{array}{l}\text { Ratio of absolute neutrophil count } \\
\text { (ANC) to absolute lymphocyte } \\
\text { Count (ALC) }\end{array}$ \\
$\begin{array}{l}\text { Acute phase protein secreted in the } \\
\text { liver in response to signals such as } \\
\text { IL6. Activates complement system }\end{array}$
\end{tabular}

Interleukin 6 (IL-6)

\section{Pro-inflammatory cytokine. Mediator of acute phase response and of fever}

\begin{tabular}{l} 
Use in oncology \\
\hline Associated with poor prognosis, \\
disease recurrence in multiple \\
tumor types \\
Associated with increased risk of \\
cancer, disease progression, and \\
reduced survival in cancer patients \\
Elevated baseline levels present in \\
cancer patients, associated with \\
poor response to immunotherapy
\end{tabular}

\begin{tabular}{l}
\hline Use in CovID-19 \\
\hline Reported to identify severe \\
COVID-19 illness at an early \\
stage \\
Elevated CRP associated with \\
increased need for \\
mechanical ventilation in \\
COVID-19 patients \\
Elevated serum levels \\
associated with severe \\
outcomes in COVID-19 \\
patients
\end{tabular}

For example, elevated NLR has been associated with a poor prognosis in a number of tumor types (Templeton et al. 2014, Baum et al. 2016, Diem et al. 2017, Bilen et al. 2018, Duan et al. 2018, Yin et al. 2019), as well as with inferior responses to checkpoint blockade or CAR-T therapy (Saied et al. 2014, Diem et al. 2017, Bilen et al. 2019).

C-reactive protein (CRP) is another serum inflammatory marker studied in numerous infections (e.g. malaria, influenza) (Vasileva \& Badawi 2019, AddaiMensah et al. 2019), and CRP has been reported to correlate with risk for and outcomes in chronic conditions such as diabetes, hypertension, and cardiovascular disease (King et al. 2003, Ridker et al. 2005, Jain et al. 2011, Hage 2014). Indeed, CRP has also been employed as an inflammatory biomarker in patients with cancer. Elevated CRP has been associated with increased risk of cancer (Siemes et al. 2006), with cancer progression (Hall et al. 2013, Weber et al. 2019), and with reduced survival in cancer patients (Allin et al. 2011, Weber et al. 2019, Iivanainen et al. 2019).

While there are numerous mechanisms that may cause elevation of CRP, increased IL- 6 related signaling is well established as a driver of elevated CRP (Moore \& June 2020). As such, IL-6 levels are followed as an inflammatory biomarker. Elevated serum IL-6 levels have been reported in patients with breast, cervical, esophageal, head and neck, ovarian, pancreatic, prostate, and renal cancers (Johnson et al. 2018). Moreover, elevated serum IL-6 predicted poor prognosis in a number of cancer types (Johnson et al. 2018, Weber et al. 2019) and has been associated with poor response to immune checkpoint blockade (Weber et al. 2019). Conversely, low levels of IL-6 have been associated with positive responses to CAR-T cell therapy in hepatocellular carcinoma (Enblad et al. 2018). High levels of IL-6 are associated with increased incidence of adverse events in patients receiving immunotherapy (Johnson et al. 2018), as well as with occurrence of cytokine release syndrome (CRS) in patients receiving CAR-T cell therapy
(Neelapu et al. 2018), and use of anti-IL6 regimens (e.g. tocilizumab) have proven successful in mitigating the mal-effects of CRS (Maude et al. 2014).

Not surprisingly, elevated blood inflammatory markers have recently been reported in COVID-19 patients. In a preliminary study, NLR was reported to enable early identification of severe illness (Liu et al. 2020a). Similarly, elevated serum IL-6 has been associated with severe outcomes in COVID-19 patients, such as respiratory failure and acute respiratory distress syndrome (Chen et al. 2020, Ruan et al. 2020). Increased serum IL-6 and CRP levels have also been associated with increased need for mechanical ventilation (Liu et al. 2020b, Herold et al. 2020). CRS has also been reported as a complication of SARS-CoV-2 infection (Chen et al. 2020, Ruan et al. 2020, Moore \& June 2020).

The corresponding trends in inflammatory markers in cancer and COVID-19 raise a number of questions. Could cancer patients be at a higher risk of severe complications of SARS-CoV-2 infection due to an already elevated baseline inflammatory marker status? Or could the inflammatory state associated with severe COViD-19 precipitate cancer progression or impair the response to therapy? Preliminary reports suggest cancer patients may experience severe complications of SARS-CoV-2 infection at a higher rate (Dai et al. 2020, Liang et al. 2020, Zhang et al.). For example, as of February 28, 2020, the WHO-China Joint Mission on COVID-19 reports a crude fatality ratio (CRF) of $7.6 \%$ for patients with cancer as a comorbid condition and laboratory-confirmed infection, compared to an overall CFR of 3.8\% (https://www.who. int/publications-detail/report-of-the-who-china-jointmission-on-coronavirus-disease-2019-(covid-19)). More investigation is needed to determine the etiology of the apparent elevated risk for severe COVID-19 outcomes in cancer patients and if a baseline inflammatory state may contribute to this risk. There are also supportive care
C) 2020 Society for Endocrinology Published by Bioscientifica Ltd. Printed in Great Britain 
treatment implications, and with the successful use of anti-IL6 regimens in cancer-related CRS, anti-IL6 agents are being investigated for use in COVID-19 patients with critical complications. Preliminary studies report decreased fever and reduced oxygen requirements in COVID-19 patients receiving anti-IL6 therapy (Xu et al. 2020). Several global clinical trials are ongoing to further investigate the potential of anti-IL6 therapy for severe SARS-CoV-2 infections (Genentech, Sanofi/Regeneron).

As with T-cell activation biomarkers, systemic inflammatory biomarkers are non-specific readouts of immunobiology, whether in the setting of cancer or COVID-19. Accordingly, careful annotation of clinical data will be necessary to enable accurate interpretation of clinical trials data collected during and following this pandemic. Additionally, knowledge of elevated inflammatory markers at baseline in a number of conditions, such as cancer, should be considered in the study of clinical data correlates in COVID-19 patients.

\section{Clinical and research program considerations}

As highlighted by the limited data currently available, patients with solid tumors are generally older, have other medical comorbidities, and may be functionally immunosuppressed from their disease or treatment or both, putting them in the highest risk category for severe outcomes with COVID-19. Patients with potentially curable malignancy should be approached differently than those with progressive metastatic disease after multiple lines of therapy and declining functional status. This has critical implications for the timing of discussions around transitioning care to palliation and/or hospice. In effort to limit further spread, some hospital systems are making the tough decision to restrict or deny any visitors, which can be heartbreaking for patients at the end of life, whether due to SARS-COV-2 or their cancer.

For patients who need to continue on treatment, multiple consensus-based guidelines are beginning to direct clinicians (https://www.dana-farber.org/ uploadedFiles/Pages/COVID-19_Facts_and_Resources/ gu-cancer-covid-19-guidelines.pdf; https://www.esmo. org/guidelines/cancer-patient-management-duringthe-covid-19-pandemic; https://www.nccn.org/covid19/). Overall, the general goals are to avoid, if possible, immunosuppressive steroids, minimize hospital exposure when safely feasible, and use growth-factor support in patients who are receiving systemic cytotoxic chemotherapy at risk for neutropenia. The individual tumor type, stage, and line/intent of treatment inform decision making for treatment modification if necessary or access to care. For example, kidney cancer patients with suspected significant immune-mediated side effects, large or critically located renal masses that cause symptoms, or cancer-related emergencies (such as spinal cord compression or progressive brain metastasis) need to be high priority for medical care (https://www.esmo.org/ guidelines/cancer-patient-management-during-the-covid19-pandemic/genitourinary-cancers-renal-cell-cancer-inthe-covid-19-era). However, patients with favorable risk disease, good tolerance on an established treatment (such as VEGF targeted therapy or immunotherapy) or in longterm follow-up can be safely followed by telemedicine or deferred for later in-person visits (https://www.esmo. org/guidelines/cancer-patient-management-during-thecovid-19-pandemic/genitourinary-cancers-renal-cellcancer-in-the-covid-19-era; https://www.dana-farber.org/ uploadedFiles/Pages/COVID-19_Facts_and_Resources/ gu-cancer-covid-19-guidelines.pdf). For patients with resected early stage lung cancer (T2bN0) or over the age of 70 with medical comorbidities, omission or delay of adjuvant chemotherapy may be considered. In advanced non-small cell lung cancer, data for the use of singleagent immunotherapy if PD-L1 $\geq 1 \%$ may enable patients to delay cytotoxic therapy (Mok et al. 2019). Treatment intervals with single-agent immunotherapy may also be extended from 2 to 4 weeks with nivolumab or 3 to 6 weeks with pembrolizumab (Long et al. 2018, Lala et al. 2018, FDA). Patients on immunotherapy who have achieved complete or partial response and completed 12-18 months of therapy can consider longer delays and, given the lack of prospective data, those who have completed 2 years may move to surveillance (https://www.esmo.org/ guidelines/cancer-patient-management-during-the-covid19-pandemic/lung-cancer-in-the-covid-19-era).

In a time of such uncertainty, clinical trials, especially early stage, carry the additional burden of potentially unknown side-effect profiles and associated frequent visits for lab monitoring. This is not to say that these trials are too risky to be considered. In patients with progressive cancer and good performance status with no standard-ofcare therapeutic options, the risk of dying of their cancer is a near certainty, while succumbing to SARS-CoV-2 is a possibility. Both pharmaceutical and institutional sponsors of clinical trials are making practical accommodations to limit interactions with the healthcare system while maintaining safety on studies. This has been supported by the FDA guidance document on the conduct of clinical trials during this public health emergency 
(https://www.fda.gov/regulatory-information/ search-fda-guidance-documents/fda-guidanceconduct-clinical-trials-medical-products-during-covid-19public-health-emergency). Accordingly, some sponsors are waiving certain lab-only visits or allowing patients to get blood tested locally rather than requiring central testing. When resource need - whether for invasive procedures, production of novel agents, or clinical oversight - exceeds capacity, trials are pausing enrollment of new patients to focus on patients already on treatment.

\section{Conclusions}

In conclusion, obtaining accurate, well-annotated data from both patient registries and clinical trials are now more essential than ever, and an added challenge in carefully annotating these datasets will be the varied policies and practices in SARS-CoV-2 surveillance and testing throughout the world. Clearly, clinical outcomes may be skewed by SARS-CoV-2 infection. Biomarkers of immune response may also be uninterpretable, as the robust immune response to acute viral infection could confound possible cancer-specific immune responses. Clinical and laboratory data need to be meticulously annotated with timing of suspected or confirmed SARS-CoV-2 infection so that erroneous conclusions are not drawn. Due to the possibility of asymptomatic infection, even in higher risk cancer patients, post hoc analysis of COVID-19 status will be informative. With careful and thorough analysis accounting for viral immune effects, immunotherapy research can, even amidst a global pandemic, continue to inform cancer care.

\section{Declaration of interest}

Mehmet A Bilen has acted as a paid consultant for and/or as a member of the advisory boards of Exelixis, Bayer, BMS, Eisai, Pfizer, AstraZeneca, Janssen, Genomic Health, Nektar, and Sanofi and has received grants to his institution from Xencor, Bayer, Bristol-Myers Squibb, Genentech/Roche, Seattle Genetics, Incyte, Nektar, AstraZeneca, Tricon Pharmaceuticals, Peleton Therapeutics, and Pfizer for work performed outside of the present manuscript.

\section{Funding}

The authors' work is supported by funding from $\mathrm{NCl}$ grants 1-R00CA197891 (H K) and 1-F30-CA-243250 (C S J).

\section{Author contribution statement}

C S J, J W C, M A B, and H K conceived and composed the manuscript. C S $\mathrm{J}$ created the accompanying figures. All authors reviewed the manuscript.

\section{References}

Addai-Mensah O, Annani-Akollor ME, Fondjo LA, Anto EO, Gyamfi D, Sallah L, Agama D, Djabatey R \& Owiredu E-W 2019 High-sensitivity C-reactive protein: a potential ancillary biomarker for malaria diagnosis and morbidity. Disease Markers 2019 1408031. (https://doi. org/10.1155/2019/1408031)

Ahn E, Araki K, Hashimoto M, Li W, Riley JL, Cheung J, Sharpe AH, Freeman GJ, Irving BA \& Ahmed R 2018 Role of PD-1 during effector CD8 T cell differentiation. PNAS 115 4749. (https://doi.org/10.1073/ pnas.1718217115)

Akondy RS, Monson ND, Miller JD, Edupuganti S, Teuwen D, Wu H, Quyyumi F, Garg S, Altman JD, Del Rio C, et al. 2009 The yellow fever virus vaccine induces a broad and polyfunctional human memory CD8+ T cell response. Journal of Immunology 1837919 7930. (https://doi.org/10.4049/jimmunol.0803903)

Allin KH, Nordestgaard BG, Flyger H \& Bojesen SE 2011 Elevated pretreatment levels of plasma C-reactive protein are associated with poor prognosis after breast cancer: a cohort study. Breast Cancer Research 13 R55. (https://doi.org/10.1186/bcr2891)

Appay V, Dunbar PR, Callan M, Klenerman P, Gillespie GM, Papagno L, Ogg GS, King A, Lechner F, Spina CA, et al. 2002 Memory CD8+ T cells vary in differentiation phenotype in different persistent virus infections. Nature Medicine 8 379-385. (https://doi.org/10.1038/ nm0402-379)

Baum YS, Patil D, Huang JH, Spetka S, Torlak M, Nieh PT, Alemozaffar M, Ogan K \& Master VA 2016 Elevated preoperative neutrophil-to-lymphocyte ratio may be associated with decreased overall survival in patients with metastatic clear cell renal cell carcinoma undergoing cytoreductive nephrectomy. Asian Journal of Urology 3 20-25. (https://doi.org/10.1016/j.ajur.2015.09.004)

Bilen MA, Dutcher GMA, Liu Y, Ravindranathan D, Kissick HT, Carthon BC, Kucuk O, Harris WB \& Master VA 2018 Association between pretreatment neutrophil-to-lymphocyte ratio and outcome of patients with metastatic renal-cell carcinoma treated with nivolumab. Clinical Genitourinary Cancer 16 E563-E575. (https://doi. org/10.1016/j.clgc.2017.12.015)

Bilen MA, Martini DJ, Liu Y, Lewis C, Collins HH, Shabto JM, Akce M, Kissick HT, Carthon BC, Shaib WL, et al. 2019 The prognostic and predictive impact of inflammatory biomarkers in patients who have advanced-stage cancer treated with immunotherapy. Cancer 125 127-134. (https://doi.org/10.1002/cncr.31778)

Bruno S \& Darzynkiewicz Z 1992 Cell cycle dependent expression and stability of the nuclear protein detected by KI-67 antibody in HL-60 cells. Cell Proliferation 25 31-40. (https://doi. org/10.1111/j.1365-2184.1992.tb01435.x)

Butz E A \& Bevan MJ 1998 Massive expansion of antigen-specific CD8+ $\mathrm{T}$ cells during an acute virus infection. Immunity 8 167-75. (https:// doi.org/10.1016/S1074-7613(00)80469-0)

Callan MFC, Tan L, Annels N, Ogg GS, Wilson JDK, O'Callaghan CA, Steven N, Mcmichael AJ \& Rickinson AB 1998 Direct visualization of antigen-specific CD8+T cells during the primary immune response to Epstein-Barr virus in vivo. Journal of Experimental Medicine $\mathbf{1 8 7}$ 1395-1402. (https://doi.org/10.1084/jem.187.9.1395)

Chandrashekara S, Mukhtar Ahmad M, Renuka P, Anupama KR \& Renuka K 2017 Characterization of neutrophil-to-lymphocyte ratio as a measure of inflammation in rheumatoid arthritis. International Journal of Rheumatic Diseases 20 1457-1467. (https://doi. org/10.1111/1756-185X.13157)

Chen G, Wu D, Guo W, Cao Y, Huang D, Wang H, Wang T, Zhang X, Chen H, Yu H, et al. 2020 Clinical and immunological features of severe and moderate coronavirus disease 2019. Journal of Clinical Investigation 130 2620-2629. (https://doi.org/10.1172/JCI137244)

Chen P-Y, Wu CY-J, Fang J-H, Chen H-C, Feng L-Y, Huang C-Y, Wei K-C, Fang J-Y \& Lin C-Y 2019 Functional change of effector tumorinfiltrating CCR5+CD38+HLA-DR+CD8+ T cells in glioma https://erc bioscientifica com

https://doi.org/10.1530/ERC-20-0187
C) 2020 Society for Endocrinology Published by Bioscientifica Ltd. Printed in Great Britain 
microenvironment. Frontiers in Immunology 10 2395. (https://doi. org/10.3389/fimmu.2019.02395)

Dai M, Liu D, Liu M, Zhou F, Li G, Chen Z, Zhang Z, You H, Wu M, Zheng $Q$, et al. 2020 Patients with cancer appear more vulnerable to SARS-CoV-2: a multi-center study during the COVID-19 outbreak. Cancer Discovery 10 783-791. (https://doi.org/10.1158/2159-8290. cd-20-0422)

Daud AI, Loo K, Pauli ML, Sanchez-Rodriguez R, Sandoval PM, Taravati K, Tsai K, Nosrati A, Nardo L, Alvarado MD, et al. 2016 Tumor immune profiling predicts response to anti-PD-1 therapy in human melanoma. Journal of Clinical Investigation 126 3447-3452. (https://doi.org/10.1172/jci87324)

Diem S, Schmid S, Krapf M, Flatz L, Born D, Jochum W, Templeton AJ \& Früh M 2017 Neutrophil-to-lymphocyte ratio (NLR) and plateletto-lymphocyte ratio (PLR) as prognostic markers in patients with non-small cell lung cancer (NSCLC) treated with nivolumab. Lung Cancer 111 176-181. (https://doi.org/10.1016/j. lungcan.2017.07.024)

Doherty PC 1998 Update: the numbers game for virus-specific CD8+ T cells. Science 280 227. (https://doi.org/10.1126/science.280.5361.227)

Duan J, Pan L \& Yang M 2018 Preoperative elevated neutrophil-tolymphocyte ratio (NLR) and derived NLR are associated with poor prognosis in patients with breast cancer: a meta-analysis. Medicine $\mathbf{9 7}$ E13340. (https://doi.org/10.1097/MD.0000000000013340)

Enblad G, Karlsson H, Gammelgard G, Wenthe J, Lovgren T, Amini R-M, Wikstrom KI, Essand M, Savoldo B, Hallbook H, et al. 2018 A phase I/IIa trial using CD19-targeted third generation CAR T cells for lymphoma and leukemia. Clinical Cancer Research 24 6185-6194. (https://doi.org/10.1158/1078-0432.CCR-18-0426)

Gibson PH, Croal BL, Cuthbertson BH, Small GR, Ifezulike AI, Gibson G, Jeffrey RR, Buchan KG, El-Shafei H \& Hillis GS 2007 Preoperative neutrophil-lymphocyte ratio and outcome from coronary artery bypass grafting. American Heart Journal 154 995-1002. (https://doi. org/10.1016/j.ahj.2007.06.043)

Goyal N, Tsivgoulis G, Chang Jason J, Malhotra K, Pandhi A, Ishfaq Muhammad F, Alsbrook D, Arthur Adam S, Elijovich L \& Alexandrov Andrei V 2018 Admission neutrophil-to-lymphocyte ratio as a prognostic biomarker of outcomes in large vessel occlusion strokes. Stroke 49 1985-1987. (https://doi.org/10.1161/

STROKEAHA.118.021477)

Hage F G 2014 C-reactive protein and hypertension. Journal of Human Hypertension 28 410-415. (https://doi.org/10.1038/jhh.2013.111)

Hall WA, Nickleach DC, Master VA, Prabhu RS, Rossi PJ, Godette K, Cooper S \& Jani AB 2013 The association between C-reactive protein (CRP) level and biochemical failure-free survival in patients after radiation therapy for nonmetastatic adenocarcinoma of the prostate. Cancer 119 3272-3279. (https://doi.org/10.1002/cncr.28185)

Hashimoto M, Kamphorst AO, Im SJ, Kissick HT, Pillai RN, Ramalingam SS, Araki K \& Ahmed R 2018 CD8 T cell exhaustion in chronic infection and cancer: opportunities for interventions. Annual Review of Medicine 69 301-318. (https://doi.org/10.1146/annurevmed-012017-043208)

Herold T, Jurinovic V, Arnreich C, Lipworth BJ, Hellmuth JC, von Bergwelt-Baildon M, Klein M \& Weinberger T 2020 Elevated levels of IL-6 and CRP predict the need for mechanical ventilation in COVID-19. Journal of Allergy and Clinical Immunology [epub]. (https:// doi.org/10.1016/j.jaci.2020.05.008)

Huang AC, Postow MA, Orlowski RJ, Mick R, Bengsch B, Manne S, Xu W, Harmon S, Giles JR, Wenz B, et al. 2017 T-cell invigoration to tumour burden ratio associated with anti-PD-1 response. Nature $\mathbf{5 4 5}$ 60-65. (https://doi.org/10.1038/nature22079)

Iivanainen S, Ahvonen J, Knuuttila A, Tiainen S \& Koivunen JP 2019 Elevated CRP levels indicate poor progression-free and overall survival on cancer patients treated with PD-1 inhibitors. Esmo Open 4 e000531. (https://doi.org/10.1136/esmoopen-2019-000531)
Jain S, Gautam V \& Naseem S 2011 Acute-phase proteins: as diagnostic tool. Journal of Pharmacy and Bioallied Sciences 3 118-127. (https:// doi.org/10.4103/0975-7406.76489)

Jansen CS, Prokhnevska N, Master VA, Sanda MG, Carlisle JW, Bilen MA, Cardenas M, Wilkinson S, Lake R, Sowalsky AG, et al. 2019 An intra-tumoral niche maintains and differentiates stem-like CD8 T cells. Nature 576 465-470. (https://doi.org/10.1038/s41586019-1836-5)

Johnson DE, O'Keefe RA \& Grandis JR 2018 Targeting the IL-6/JAK/ STAT3 signalling axis in cancer. Nature Reviews Clinical Oncology 15 234-248. (https://doi.org/10.1038/nrclinonc.2018.8)

Kaech SM \& Ahmed R 2001 Memory CD8+ T cell differentiation: initial antigen encounter triggers a developmental program in naive cells. Nature Immunology 2 415-422. (https://doi.org/10.1038/87720)

Kaech SM, Wherry EJ \& Ahmed R 2002 Effector and memory T-cell differentiation: implications for vaccine development. Nature Reviews Immunology 2 251-262. (https://doi.org/10.1038/nri778)

Kalia V, Sarkar S, Gourley TS, Rouse BT \& Ahmed R 2006 Differentiation of memory B and T cells. Current Opinion in Immunology 18 255-264. (https://doi.org/10.1016/j.coi.2006.03.020)

Kamphorst AO, Pillai RN, Yang S, Nasti TH, Akondy RS, Wieland A, Sica GL, Yu K, Koenig L, Patel NT, et al. 2017 Proliferation of PD-1+ CD8 T cells in peripheral blood after PD-1-targeted therapy in lung cancer patients. PNAS 114 4993-4998. (https://doi.org/10.1073/ pnas.1705327114)

King DE, Mainous AG 3rd, Buchanan TA \& Pearson WS 2003 C-reactive protein and glycemic control in adults with diabetes. Diabetes Care 26 1535-1539. (https://doi.org/10.2337/diacare.26.5.1535)

Kovacsovics-Bankowski M, Chisholm L, Vercellini J, Tucker CG, Montler R, Haley D, Newell P, Ma J, Tseng P, Wolf R, et al. 2014 Detailed characterization of tumor infiltrating lymphocytes in two distinct human solid malignancies show phenotypic similarities. Journal for Immunotherapy of Cancer 2 38. (https://doi.org/10.1186/ s40425-014-0038-9)

Lala M, Li M, Sinha V, De Alwis D, Chartash E \& Jain L 2018 A sixweekly (Q6W) dosing schedule for pembrolizumab based on an exposure-response (E-R) evaluation using modeling and simulation. Journal of Clinical Oncology 36 3062-3062. (https://doi.org/10.1200/ JCO.2018.36.15_suppl.3062)

Lechner F, Wong DKH, Dunbar PR, Chapman R, Chung RT, Dohrenwend P, Robbins G, Phillips R, Klenerman P \& Walker BD 2000 Analysis of successful immune responses in persons infected with hepatitis C virus. Journal of Experimental Medicine 191 1499-1512. (https://doi.org/10.1084/jem.191.9.1499)

Lewis MA 2020 Between Scylla and Charybdis - oncologic decision making in the time of Covid-19. New England Journal of Medicine 382 2285-2287. (https://doi.org/10.1056/NEJMp2006588)

Liang W, Guan W, Chen R, Wang W, Li J, Xu K, Li C, Ai Q, Lu W, Liang H, et al. 2020 Cancer patients in SARS-CoV-2 infection: a nationwide analysis in China. Lancet Oncology 21 335-337. (https:// doi.org/10.1016/S1470-2045(20)30096-6)

Liu J, Liu Y, Xiang P, Pu L, Xiong H, Li C, Zhang M, Tan J, Xu Y, Song R, et al. 2020a Neutrophil-to-lymphocyte ratio predicts critical illness patients with 2019 coronavirus disease in the early stage. Journal of Translational Medicine 18 206. (https://doi.org/10.1186/s12967-02002374-0)

Liu T, Zhang J, Yang Y, Ma H, Li Z, Zhang J, Cheng J, Zhang X, Zhao Y, Xia Z, et al. $2020 b$ The role of interleukin-6 in monitoring severe case of coronavirus disease 2019. EMBO Molecular Medicine 12 e12421. (https://doi.org/10.15252/emmm.202012421)

Long GV, Tykodi SS, Schneider JG, Garbe C, Gravis G, Rashford M, Agrawal S, Grigoryeva E, Bello A, Roy A, et al. 2018 Assessment of nivolumab exposure and clinical safety of $480 \mathrm{mg}$ every 4 weeks flatdosing schedule in patients with cancer. Annals of Oncology 29 2208-2213. (https://doi.org/10.1093/annonc/mdy408) https://erc.bioscientifica.com

https://doi.org/10.1530/ERC-20-0187 (c) 2020 Society for Endocrinology Published by Bioscientifica Ltd. Printed in Great Britain 
Maude SL, Barrett D, Teachey DT \& Grupp SA 2014 Managing cytokine release syndrome associated with novel T cell-engaging therapies. Cancer Journal 20 119-122. (https://doi.org/10.1097/ PPO.0000000000000035)

McElroy AK, Akondy RS, Davis CW, Ellebedy AH, Mehta AK, Kraft CS, Lyon GM, Ribner BS, Varkey, J, Sidney, J, et al. 2015 Human Ebola virus infection results in substantial immune activation. PNAS 112 4719-4724. (https://doi.org/10.1073/pnas.1502619112)

Miller JD, Van Der Most RG, Akondy RS, Glidewell JT, Albott S, Masopust D, Murali-Krishna K, Mahar PL, Edupuganti S, Lalor S, et al. 2008 Human effector and memory CD8+ T cell responses to smallpox and yellow fever vaccines. Immunity 28 710-722. (https:// doi.org/10.1016/j.immuni.2008.02.020)

Mok TSK, Wu YL, Kudaba I, Kowalski DM, Cho BC, Turna HZ, Castro G Jr, Srimuninnimit V, Laktionov KK, Bondarenko I, et al. 2019 Pembrolizumab versus chemotherapy for previously untreated, PD-L1-expressing, locally advanced or metastatic non-small-cell lung cancer (KEYNOTE-042): a randomised, open-label, controlled, phase 3 trial. Lancet 393 1819-1830. (https://doi.org/10.1016/S01406736(18)32409-7)

Moore JB \& June CH 2020 Cytokine release syndrome in severe COVID19. Science 368 473. (https://doi.org/10.1126/science.abb8925)

Murali-Krishna K, Altman JD, Suresh M, Sourdive DJ, Zajac AJ, Miller JD, Slansky J \& Ahmed R 1998 Counting antigen-specific CD8 T cells: a reevaluation of bystander activation during viral infection. Immunity 8 177-187. (https://doi.org/10.1016/S1074-7613(00)80470-7)

Nakano O, Sato M, Naito Y, Suzuki K, Orikasa S, Aizawa M, Suzuki Y, Shintaku I, Nagura H \& Ohtani H 2001 Proliferative activity of intratumoral CD8+ $\mathrm{T}$-lymphocytes as a prognostic factor in human renal cell carcinoma: clinicopathologic demonstration of antitumor immunity. Cancer Research 61 5132-5136.

Neelapu SS, Locke FL \& Go WY 2018 CAR T-cell therapy in large B-cell lymphoma. New England Journal of Medicine 378 1065. (https://doi. org/10.1056/NEJMc1800913)

Ridker PM, Rifai N, Cook NR, Bradwin G \& Buring JE 2005 Non-HDL cholesterol, apolipoproteins A-I and B100, standard lipid measures, lipid ratios, and CRP as risk factors for cardiovascular disease in women. JAMA 294 326-333. (https://doi.org/10.1001/jama.294.3.326)

Ruan Q, Yang K, Wang W, Jiang L \& Song J 2020 Clinical predictors of mortality due to COVID-19 based on an analysis of data of 150 patients from Wuhan, China. Intensive Care Medicine 46 846-848. (https://doi.org/10.1007/s00134-020-05991-x)

Saied A, Licata L, Burga RA, Thorn M, Mccormack E, Stainken BF, Assanah EO, Khare PD, Davies R, Espat NJ, et al. 2014 Neutrophil:lymphocyte ratios and serum cytokine changes after hepatic artery chimeric antigen receptor-modified T-cell infusions for liver metastases. Cancer Gene Therapy 21 457-462. (https://doi. org/10.1038/cgt.2014.50)

Siemes C, Visser LE, Coebergh JW, Splinter TA, Witteman JC, Uitterlinden AG, Hofman A, Pols HA \& Stricker BH 2006 C-reactive protein levels, variation in the C-reactive protein gene, and cancer risk: the Rotterdam study. Journal of Clinical Oncology 24 5216-5222. (https://doi.org/10.1200/JCO.2006.07.1381)

Templeton AJ, Mcnamara MG, Seruga B, Vera-Badillo FE, Aneja P, Ocana A, Leibowitz-Amit R, Sonpavde G, Knox JJ, Tran B, et al. 2014 Prognostic role of neutrophil-to-lymphocyte ratio in solid tumors: a systematic review and meta-analysis. Journal of the National Cancer Institute 106 dju124. (https://doi.org/10.1093/jnci/dju124)

Vasileva D \& Badawi A 2019 C-reactive protein as a biomarker of severe H1N1 influenza. Inflammation Research 68 39-46. (https://doi. org/10.1007/s00011-018-1188-x)

Weber JS, Tang H, Hippeli L, Qian M, Wind-Rotolo M, Larkin JMG, Wolchok JD, Sznol M, Robert C, Woods DM, et al. 2019 Serum IL-6 and CRP as prognostic factors in melanoma patients receiving single agent and combination checkpoint inhibition. Journal of Clinical Oncology 37 100-100. (https://doi.org/10.1200/JCO.2019.37.15_ suppl.100)

Wieland A, Kamphorst AO, Adsay NV, Masor JJ, Sarmiento J, Nasti TH, Darko S, Douek DC, Xue Y, Curran WJ, et al. 2018 T cell receptor sequencing of activated CD8 T cells in the blood identifies tumorinfiltrating clones that expand after PD-1 therapy and radiation in a melanoma patient. Cancer Immunology, Immunotherapy 67 1767-1776. (https://doi.org/10.1007/s00262-018-2228-7)

Xu X, Han M, Li T, Sun W, Wang D, Fu B, Zhou Y, Zheng X, Yang Y, Li X, et al. 2020 Effective treatment of severe COVID-19 patients with tocilizumab. PNAS 117 10970-10975. (https://doi.org/10.1073/ pnas.2005615117)

Ye Z, Ai X, Liao Z, You C. \& Cheng Y 2019 The prognostic values of neutrophil to lymphocyte ratio for outcomes in chronic obstructive pulmonary disease. Medicine 98 E16371. (https://doi.org/10.1097/ MD.0000000000016371)

Yin X, Wu L, Yang H \& Yang H 2019 Prognostic significance of neutrophil-lymphocyte ratio (NLR) in patients with ovarian cancer: a systematic review and meta-analysis. Medicine 98 E17475. (https:// doi.org/10.1097/MD.0000000000017475)

Zhang L, Zhu F, Xie L, Wang C, Wang J, Chen R, Jia P, Guan HQ Peng L, Chen Y, et al. 2020 Clinical characteristics of COVID-19infected cancer patients: a retrospective case study in three hospitals within Wuhan, China. Annals of Oncology 31 894-901. (https://doi. org/10.1016/j.annonc.2020.03.296)

Received in final form 28 May 2020

Accepted 1 June 2020

Accepted Manuscript published online 5 June 2020
C) 2020 Society for Endocrinology Published by Bioscientifica Ltd. Printed in Great Britain 